SCIREA Journal of Health

http://www.scirea.org/journal/PMH

October 24, 2021

Volume 5, Issue 5, October 2021

\title{
Ultrasound of the Optical Nerve Sheath Diameter as an Indicator of the Increase of the Intracranial Pressure (ICP) in patients with Traumatic Brain Injury
}

\author{
Karen Itzel González-Martínez ${ }^{1}$, Aldo Giovanni Cerón-Solano ${ }^{2}$, David Rafael Cañez- \\ Martínez $^{3}$, Francisco Javier López-Parra ${ }^{1}$, Luis Eduardo Bejarano-López ${ }^{1}$ \\ 1 Department of Emergency Medicine, General Hospital of Mexicalli, Autonomous \\ University of Baja California, Baja California, Mexico. \\ ${ }^{2}$ Department of General Surgery, General Hospital of Cuautitlan, Autonomous University of \\ the State of Mexico, Mexico. \\ ${ }^{3}$ Department of Anesthesiologist, General Hospital of Mexicalli, Autonomous University of \\ Baja California, Baja California, Mexico.
}

\begin{abstract}
Ultrasound at the bedside has gained popularity in more emergency departments and has been integrated as a central element in the training of residents. The Ocular Ultrasound was used for the detection of the Optical Nerve Sheath Diameter in the Ocular Trauma, Retinal Detachment, Intracranial Pressure and Vitreal Hemorrhage . The Ultrasound of the Optical Nerve Sheath Diameter measurement has been validated as an indirect evaluation of Intracranial Pressure. Objective To assess the quality of the ultrasound in patients with Moderate to Severe Craneoencephalic Traumatism as an Indicator of the Increase in Intracranial Pressure in the Emergency Service of the General Hospital of Mexicali. Material and methods. Prior authorization from the Research Ethics Committee,
\end{abstract}


this analytical prospective study was conducted in the emergency service of the General Hospital of Mexicali, from August 2017 to December 2018, where 43 patients with moderate and severe trauma according to the Glasgow scale were received. who underwent ultrasound of the optic nerve sheath (US DVNO) upon admission, recorded the measurement and compared with the results obtained in the tomography, Glasgow and the patient's clinical status, for the diagnosis of intracranial hypertension. Results. The 43 patients with moderate and severe TBI who underwent US DVNO, 10 patients presented DVNO $\geq 5 \mathrm{~mm}$ and 33 DVNO $<5 \mathrm{~mm}$, of those who had DVNO $\geq 5 \mathrm{~mm}, 10$ of 10 had tomographic findings of cerebral edema, and 9-10 required hospitalization, craniectomy and / or admission to ICU, those with DVNO $<5 \mathrm{~mm}, 7$ of 33 had tomographic findings of edema and in 26 of 33 no findings were found and only 3 required hospitalization. The probability of having cerebral edema with DVNO $\geq 5 \mathrm{~mm}$ is 10 to 0 (10: 0$)$, and the probability of requiring hospitalization, craniectomy and / orICU was 9 to $1(9: 1)$, while the probability of having cerebral edema with DVNO $<5 \mathrm{~mm} 7$ to 26,7 out of 26 or 1 in 3.7 patients and the probability of hospitalization, craniectomy and / or ICU was 3 to 30, that is, 3 out of 30 patients or 1 in each 10 . DVNO $\geq 5 \mathrm{~mm}$ is associated with hospitalization with error less than $1 \%$. Conclusions The US DVNO is a useful tool in the emergency department as an indicator of increased intracranial pressure in patients with traumatic brain injury, it is considered an effective, non-invasive, simple and reproducible method that can be performed at the patient's bedside and that allows us to an adequate diagnosis and treatment without delay having a positive impact on the patient's morbidity.

Keywords : Ultrasound (US), Diameter of the Optical Nerve Sheath (DVNO), Intracranial Hypertension (ICH), Intracranial pressure (ICP), Traumatic brain injury (TBI).

\section{Introduction}

Ultrasound at the bedside has gained popularity in more emergency departments and has been integrated as a central element in the training of residents. The Ocular Ultrasound was used for the detection of Ocular Trauma, Retinal Detachment, Intracranial Pressure and Vitreous Hemorrhage. 
Ultrasound of the measurement of the Diameter of the Optic Nerve Pod has been validated as an indirect evaluation of Intracranial Pressure.

Computed tomography is preferred as the study of first choice for the detection of intracranial events in the emergency department, however, in various situations this cannot be performed, and the physical examination is not satisfactory to determine the increase in intracranial pressure, especially in unconscious patients, intubated or with hemodynamic instability. The invasive monitoring of the ICP continues to be the gold standard for the diagnosis of intracranial hypertension ( $\mathrm{ICH}$ ), however this technique can have serious complications such as hemorrhage and bacterial colonization, therefore the monitoring of the ICP by ultrasound is considered a non-invasive, simple, reproducible technique and can be performed to the patient's bed, important advantage in unstable patients. ${ }^{[1]}$

These examinations in the emergency department are of importance in patients who require rapid diagnosis and treatment in life threatening conditions, thus considering time as a crucial factor in the decisions made, "time is brain".

During embryogenesis the optic nerve leaves the diencephalon to the orbit, with a nerve sheath consisting of 3 layers of meninges, simultaneously, the cerebrospinal fluid passes freely to the intracranial and intraorbital subarachnoid spaces, thus showing the same pressure change in space intraorbital than in the intracranial subarachnoid space.

The measurement of the diameter of the optic nerve sheath via ocular ultrasound is recently used extensively for evaluation of intracranial pressure.

This study demonstrates the effectiveness of DVNO measurement to determine intracranial pressure and possible complications or management in patients with moderate to severe TCI in the emergency department, compared with the expected changes in the cranial tomography and the coma scale of Glasgow.

The only way to determine the PIC is by measuring it. There are several monitoring methods but they are invasive. Fiber optic sensors are used that are placed in the most affected hemisphere. They allow the determination of the PIC and, secondarily, knowledge of the PAM, the PPC is obtained. The treatment thresholds of the ICP are between 20 and $15 \mathrm{mmHg}$ in the case of temporary injuries. The systems consist of a catheter that is implanted in a specific intracranial region, and is connected to a pressure gauge. The gold standard is achieved with the intraventricular catheter, which also serves as a therapeutic tool. The problem is the risk of infections that trigger as of the fifth day of 
implantation. Occasionally, due to the inability to access the ventricle due to the mass effect of the etiological lesion, ICP sensors are implanted in the epidural, subdural or intraparenchymal space; in the latter, tissue oxygen pressure is determined. The pressure collected by these alternative systems is not as reliable as that recorded through the intraventricular system. However, the USG of DVNO has been considered a non-invasive and effective method for monitoring intracranial pressure.

Ultrasonography performed by non- radiologists specialists is positioned as an economic, effective, safe, not invasive and fast tool.

Intracranial hypertension is a life-threatening condition.

The search for diagnostic aids with lower morbidity focuses on non-invasive methods, such as nuclear magnetic resonance, computerized axial tomography and transcranial Doppler ultrasound, however, the correlation of these methods with specific values of intracranial pressure is limited.

In 1965 the first report of USG eye, good predictor ICP was performed. The most distal portion of the optic nerve is covered by the dura mater forming a membrane known as the optic nerve sheath. As the ICP rises, the CSF is distributed by the dura to the optic nerve sheath, which dilates.

Ultrasound of the diameter of the optic nerve sheath was suggested as a noninvasive measure of intracranial pressure and was first described in 1987. ${ }^{[9]}$

In 1996, Helmke and Hansen reported a study about the evaluation of the optic nerve sheath in intracranial hypertension by means of transorbital ultrasound. ${ }^{[2]}$

There are several studies in which the use of ultrasound of the optic nerve sheath is supported as a non-invasive method of measuring intracranial pressure, among which studies done in healthy people and people with intracranial pathology stand out, for example:

In a prospective study with a total of 100 patients with suspected nontraumatic intracranial event, they were divided into 2 equal groups including 50 patients in group I with pathology in the skull tomography and a group II that included patients with normal tomography, the US DVNO was measured with transducers of 11 and $14 \mathrm{MHz}$, the values within group I and group II were between $5.4 \pm 1.1$ and $4.1 \pm 0.5$, the diameter of the optic nerve sheath was higher in patients with lesion in the tomography, the cutoff point for deviation of the midline 
was $5.3 \mathrm{~mm}$ (sensitivity $70 \%$ and specificity $74 \%$ ) with an area under the curve of $0.728 ; 95 \%$ confidence interval. ${ }^{[1]}$

In other, double-blind, prospective observational study in the intensive care unit, 45 patients diagnosed with cranial trauma were divided into groups, of these 19 patients had midline displacement and 26 had no intracranial pathology or midline deviation, here a significant positive correlation was demonstrated between the deviation of the midline and the DVNO. ${ }^{[2]}$ The ultrasound of the diameter of the optic nerve sheath performed in healthy subjects in 120 patients, 55 women and 65 men, obtaining an average DVNO of $3.68 \mathrm{~mm}$ (with a confidence interval of 95\%), was reported in the same way as the Measurement does not vary with age or weight or height, but with the sex of the patient. In men, a DVNO of $3.78 \mathrm{~mm}$ was obtained and in women of $3.60 \mathrm{~mm}$. This study gives us an idea of separating the reference ranges of men and women. ${ }^{[9]}$

In a prospective study in the emergency department, in a total of 65 patients, 36 men and 25 women, within an age of $56 \pm 17$ years the DVNO measurement was compared by ultrasound and by tomography, with the USG of DVNO being performed first, these measurements were certified by medical radiologists, finding a difference in DVNO measurements $\geq 0.5 \mathrm{~mm}$, which was considered significant for the study. [10]

The Association of Surgery Academy of the University of California conducted a prospective, double blind study of 145 adult patients with head trauma who required PIC monitoring, the DVNO was measured with ultrasound pre and post installation of PIC monitor, it was reached conclusion that the USG has a poor estimate of the ICP compared to the ventriculostomy catheter. [11]

In a prospective descriptive study conducted at the University of Medical Sciences of Iran, US was performed to measure DVNO before lumbar puncture in 50 non-traumatized patients who were candidates for lumbar puncture, immediately after ultrasound, the intracranial pressure of each patient was measured by lumbar puncture the correlation was used to evaluate the relationship between the ICP and DVNO by ultrasound, the DVNO measurements were $5.17 \pm 1.01$ and $5.19 \pm 1.06 \mathrm{~mm}$ in the left and right eye, the mean of DVNO in patients with an increase in the PIC and in normal patients was $6.66 \pm 0.58$ and $4.60 \pm 0.41 \mathrm{~mm}$. The DVNO greater than $5.5 \mathrm{~mm}$ predicts a $\mathrm{PIC} \geq 20 \mathrm{cmH}_{2} \mathrm{O}$. [12]

An observational, prospective, double-blind study from September 2010 to April 2011 conducted at Maricopa Medical Center, Phoenix, AZ, USA, included 150 patients who 
presented to the emergency service, 3 groups were made with 50 patients each one; Group 1; DVNO in asymptomatic /normotensive patients , Group 2; DVNO in asymptomatic / hypertensive patients and Group 3; DVNO in symptomatic / hypertensive patients, it was concluded that a blood pressure greater than $166 / 82 \mathrm{mmHg}$ is associated with higher DVNO. ${ }^{[13]}$

Within the pediatric setting there are also studies, a prospective study in pediatric patients conducted between August 2012 to December 2014 at Jacksonville Hospital, Fl. For patients between 12 to 18 years of age with suspected Idiopathic Intracranial Hypertension, the DVNO was measured before the sedation procedure, it was concluded that the presence of an DVNO $>4.5 \mathrm{~mm}$ in any eye was considered elevated in adolescents, corresponding to an eye pressure above $20 \mathrm{cmH}_{2}$ O. [14]

There are multiple studies that support the use of Ultrasound in the assessment and monitoring of ICP in patients with intracranial hypertension secondary to trauma or not, which allows early diagnosis and treatment, as well as a positive impact on the mortality of these patients.

\section{METHODOLOGY}

Prospective observational study in which patients with a diagnosis of moderate to severe cranioencephalic trauma were admitted to the Emergency Department of the General Hospital of Mexicali, US DVNO was performed upon admission as an indicator of increased intracranial pressure, for a diagnosis and fast treatment

\section{a) Sampling Frame}

\section{i. Population and Place of Realization}

Population attended in the Adult Emergency Service of the General Hospital of Mexicali.

\section{ii. Sample Size}

Not probabilistic.

\section{b) Object of Study}

Patients treated in the Emergency Service of the General Hospital of Mexicali with diagnosis of moderate and severe Traumatic Brain Injury .

\section{c) Inclusion criteria}


- Patient over 18 years old.

- History of Cranioencephalic Traumatism

- TCE diagnosis confirmed by GCS and CT scan data in the emergency department Adults Mexicali General Hospital in the period from August 2017 to December 2018

\section{d) Exclusion criteria}

- $\quad$ Patient under 18 years old

- Inability to establish diagnostic confirmation by study methods.

- $\quad$ Presence of glaucoma, Ophthalmic disease

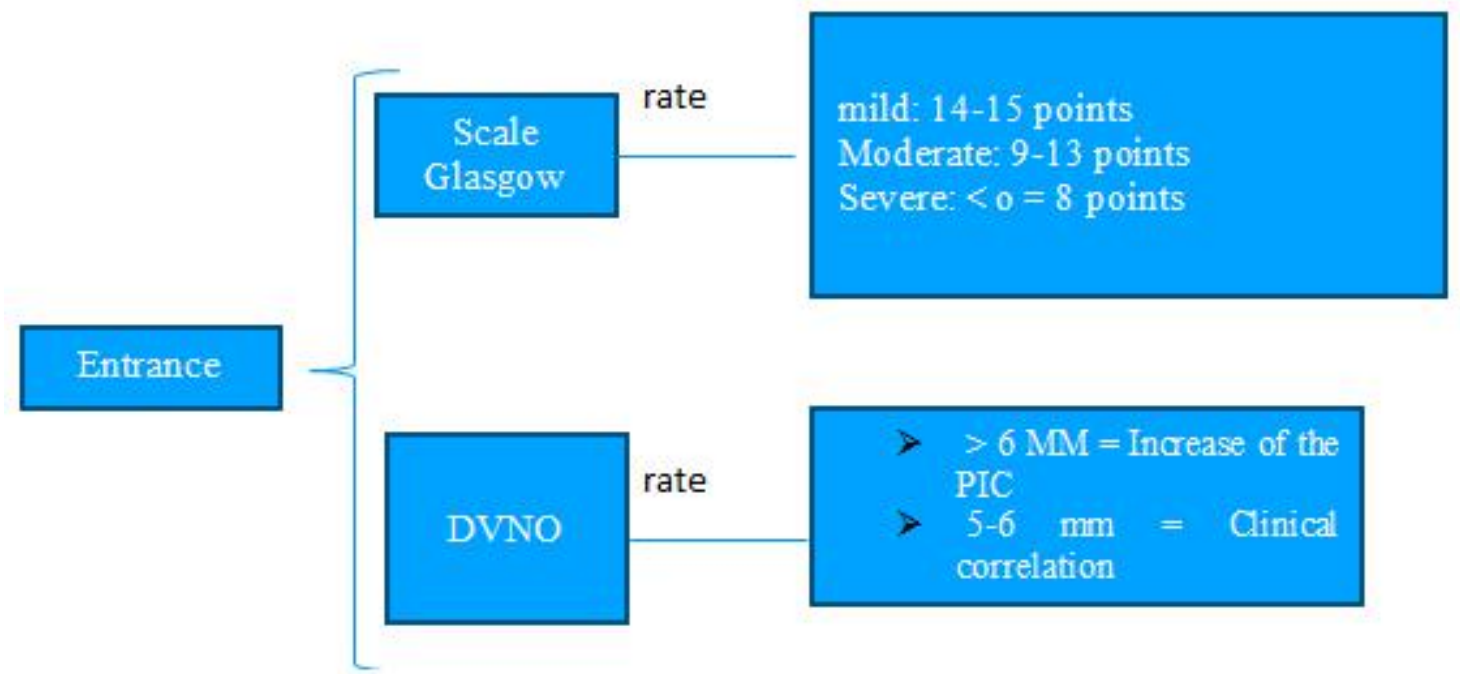

Figure 1. Patient classification according to Glasgow coma scale and DVNO

\section{RESULTS}

1) In a group of 43 patients with moderate to severe TBI, 10 had DVNO $\geq 5 \mathrm{~mm}$ and 33 DVNO $<5 \mathrm{~mm}$, of those with DVNO $\geq 5 \mathrm{~mm}, 10$ of 10 had tomographic findings of cerebral edema, those with DVNO $<5 \mathrm{~mm}, 7$ of 33 had tomographic findings of edema and in 26 of 33 no findings were found.

2) The probability of having brain edema with DVNO $\geq 5 \mathrm{~mm}$ is 10 to 0 (10:0), while the probability of having brain edema with DVNO $<5 \mathrm{~mm}$ is 7 to 26,7 of every 26 or 1 of every 3.7

3) A probability ratio (OR) cannot be calculated because 10 out of every 0 is not a rational expression. 
4) $100 \%(\mathrm{n}=10)$ of patients with DVNO $\geq 5 \mathrm{~mm}$ presented tomographic signs of edema, while only $21.2 \%$ of patients with DVNO $<5 \mathrm{~mm}$ presented tomographic signs of edema.

\begin{tabular}{|c|c|c|c|}
\hline \multicolumn{4}{|c|}{ Tomographic signs of Edema } \\
\hline & TRUE & FALSE & \\
\hline \multirow{2}{*}{ DVNO $\geq 5 \mathrm{~mm}$} & 10 & 0 & \multirow{2}{*}{10} \\
\cline { 2 - 3 } & $100 \%$ & $0 \%$ & \\
\hline DVNO<5mm & 7 & 26 & \multirow{2}{*}{33} \\
\cline { 2 - 3 } & $21.20 \%$ & $78.80 \%$ & \\
\hline & 17 & 26 & 43 \\
\hline
\end{tabular}

Figure 2. Relation of the diameter of the optic nerve sheath and tomographic signs of edema

\begin{tabular}{|c|c|c|c|c|c|c|c|}
\hline \multicolumn{7}{|c|}{ Tomographic signs of Edema } \\
\hline & TRUE & EXPECTED & CONTRIBUTION & FALSE & EXPECTED & CONTRIBUTION & \\
\hline DVNO $\geq 5 \mathrm{~mm}$ & 10 & 4 & 9.25 & 0 & 6 & 6.05 & 10 \\
\hline & & & & & & & \\
\hline DVNO $<5 \mathrm{~mm}$ & 7 & 13 & 2.8 & 26 & 20 & 1.83 & 33 \\
\hline & 17 & 17 & 12.05 & 26 & 26 & 7.88 & 43 \\
\hline
\end{tabular}

Figure 3. Probability of having brain edema with DVNO $\geq 5 \mathrm{~mm}$

Chi square 19,929 Vs. Chi square with 1 degree of freedom, p 0.000 Association statistically significant with error probability less than $1 \%$.

\begin{tabular}{|c|c|c|c|c|c|}
\hline \multicolumn{6}{|c|}{ Odds Ratio (OR) } \\
\hline \multirow{2}{*}{ DVNO $\geq 5 \mathrm{~mm}$} & 9 & 9 & \multirow{4}{*}{90} & \multirow{2}{*}{975.02} & \multirow{2}{*}{ IC 95 \% Sup } \\
\hline & 1 & J & & & \\
\hline \multirow{2}{*}{ DVNO $<5 \mathrm{~mm}$} & 3 & \multirow{2}{*}{0.1} & & \multirow{2}{*}{8.31} & \multirow{2}{*}{ IC 95\% Inf } \\
\hline & 30 & & & & \\
\hline
\end{tabular}

Figure 4. Odds Ratio DVNO

\begin{tabular}{|l|c|c|}
\hline \multicolumn{3}{|c|}{ RISK RATIO (RR) } \\
\cline { 1 - 2 } DVNO $\geq 5 \mathrm{~mm}$ & 0.9 & \multirow{2}{*}{9.9} \\
\cline { 1 - 2 } DVNO $<5 \mathrm{~mm}$ & 0.09 & \\
\hline
\end{tabular}

Figure 5. Risk Ratio DVNO

The $90 \%(\mathrm{n}=10)$ of patients with DVNO $\geq 5 \mathrm{~mm}$ required hospitalization, craniectomy and / or ICU while only $9.1 \%$ of patients with DVNO $<5 \mathrm{~mm}$ required hospitalization, craniectomy and / or ICU. 


\begin{tabular}{|c|c|c|c|}
\hline \multirow{2}{*}{$n$} & \multicolumn{3}{|c|}{ SKULL FRACTURE } \\
\cline { 2 - 4 } & TRUE & FALSE & GRAND TOTAL \\
\hline HOSPITALIZATION & 6 & 6 & 12 \\
\hline EGRESS & 5 & 26 & 31 \\
\hline GRAND TOTAL & 11 & 32 & 43 \\
\hline
\end{tabular}

The association of Skull Fracture and Hospitalization is significant with error probability less than $5 \%$
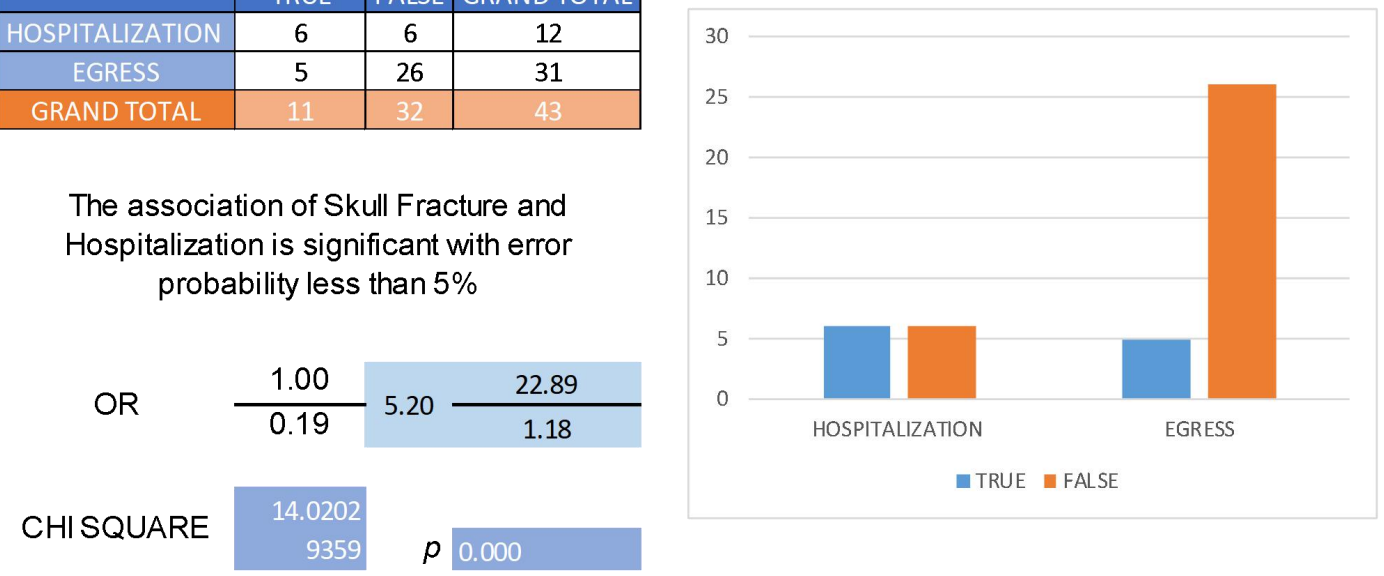

Figure 6. Relation the diameter of optic nerve and Hospitalization in patient with skull fracture

\begin{tabular}{|c|c|c|c|}
\hline \multirow{2}{*}{$n$} & \multicolumn{3}{|c|}{ FRACTURE HUNDRED } \\
\cline { 2 - 4 } & TRUE & FALSE & GRAND TOTAL \\
\hline HOSPITALIZATION & 3 & 9 & 12 \\
\hline EGRESS & 2 & 29 & 31 \\
\hline GRAND TOTAL & 5 & 38 & 43 \\
\hline
\end{tabular}

No association or independence can be determined between Sink Fracture and Hospitalization (confidence interval exceeds unity).

OR

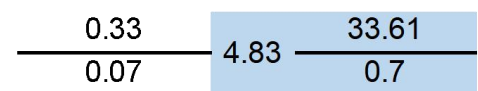

CHISQUARE

26.19268495

\section{$p 0.000$}

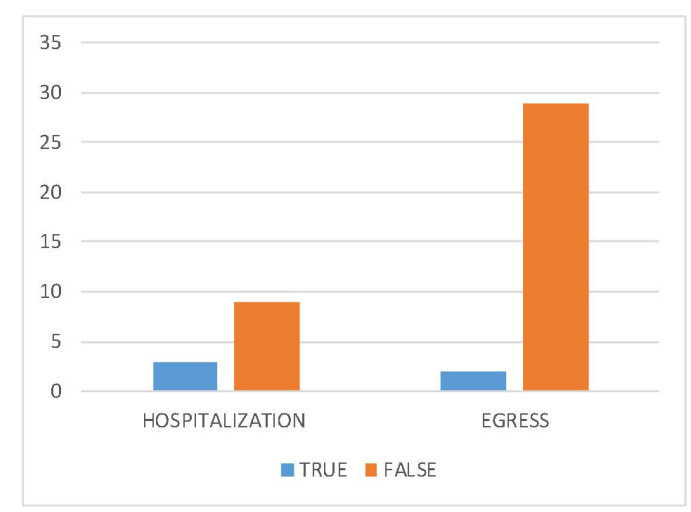

Figure 7. Relation the diameter of optic nerve and Hospitalization in patient with Fracture

\section{Hundred}

\begin{tabular}{|c|c|c|c|}
\hline \multirow{2}{*}{$n$} & \multicolumn{3}{|c|}{ CONTUSION HEMORRHAGIC } \\
\cline { 2 - 4 } & TRUE & FALSE & GRAND TOTAL \\
\hline HOSPITALIZATION & 9 & 3 & 12 \\
\hline EGRESS & 8 & 23 & 31 \\
\hline GRAND TOTAL & 17 & 26 & 43 \\
\hline
\end{tabular}

The association of Hemorrhagic Contusion and Hospitalization is significant with a probability of error of less than $5 \%$

OR

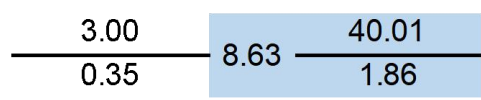

CHISQUARE

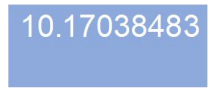

$$
\text { p } 0.001
$$

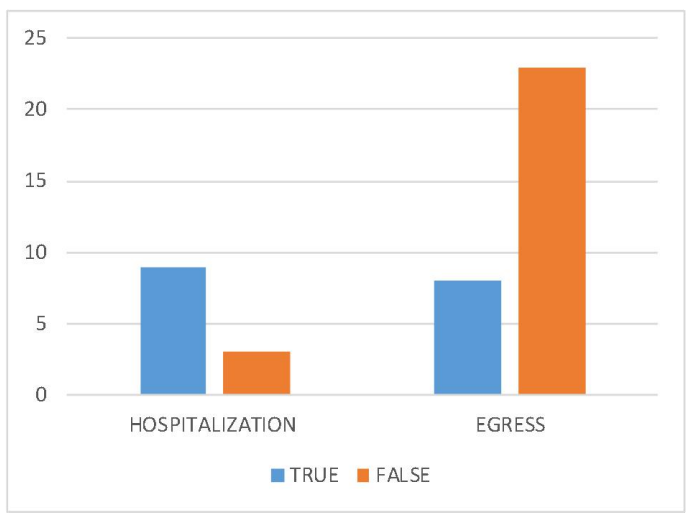

Figure 8. Relation the diameter of optic nerve and Hospitalization in patient with Contusion

\section{Hemorrhagic}




\begin{tabular}{|c|c|c|c|}
\hline \multirow{2}{*}{$n$} & \multicolumn{3}{|c|}{ SUBARACHNOID HEMORRHAGE } \\
\cline { 2 - 4 } & TRUE & FALSE & GRAND TOTAL \\
\hline HOSPITALIZATION & 5 & 7 & 12 \\
\hline EGRESS & 9 & 22 & 31 \\
\hline GRAND TOTAL & 14 & 29 & 43 \\
\hline
\end{tabular}

No association or independence between Subarachnoid Hemorrhage and Hospitalization can be determined (confidence interval exceeds unity).

OR

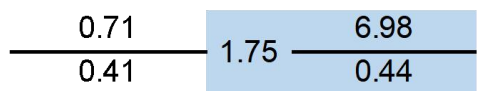

CHISQUARE

$$
5.64
$$

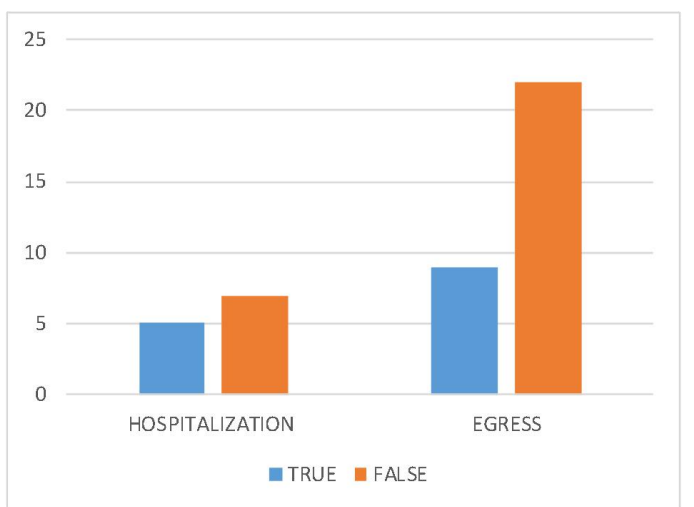

aTRUE aALSE

Figure 9. Relation the diameter of optic nerve and Hospitalization in patient with

\section{Subarachnoid Hemorrhage}

\begin{tabular}{|c|c|c|c|}
\hline \multirow{2}{*}{$n$} & \multicolumn{3}{|c|}{ EPIDURAL HEMATOMA } \\
\cline { 2 - 4 } & TRUE & FALSE & GRAND TOTAL \\
\hline HOSPITALIZATION & 4 & 8 & 12 \\
\hline EGRESS & 1 & 30 & 31 \\
\hline GRAND TOTAL & 5 & 38 & 43 \\
\hline
\end{tabular}

The association of Epidural Hematoma and Hospitalization is significant with error probability less than $5 \%$

OR

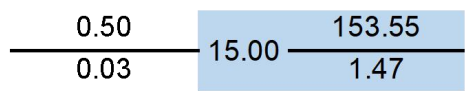

CHISQUARE

$$
28.14
$$

$$
\text { p } 0.000
$$

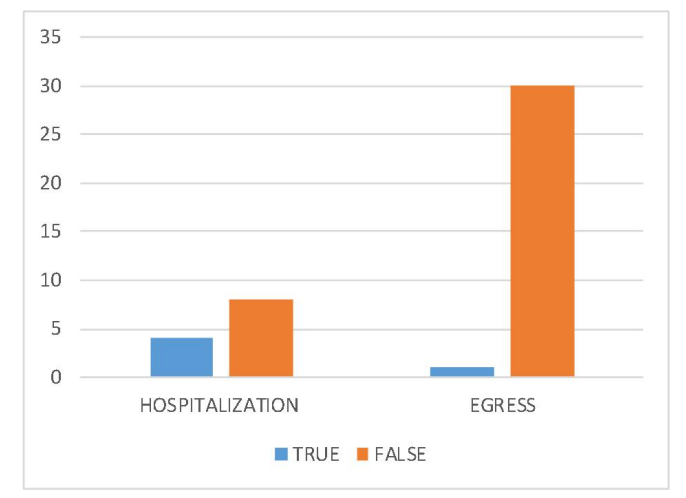

Figure 10. Relation the diameter of optic nerve and Hospitalization in patient with Epidural

\section{Hematoma}

\begin{tabular}{|c|c|c|c|}
\hline \multirow{2}{*}{$n$} & \multicolumn{3}{|c|}{ SUBDURAL HEMATOMA } \\
\cline { 2 - 4 } & TRUE & FALSE & GRAND TOTAL \\
\hline HOSPITALIZATION & 3 & 9 & $\mathbf{1 2}$ \\
\hline EGRESS & 2 & 29 & 31 \\
\hline GRAND TOTAL & 5 & 38 & 43 \\
\hline
\end{tabular}

No association or independence between Subdural Hematoma and Hospitalization can be determined (confidence interval exceeds unity).
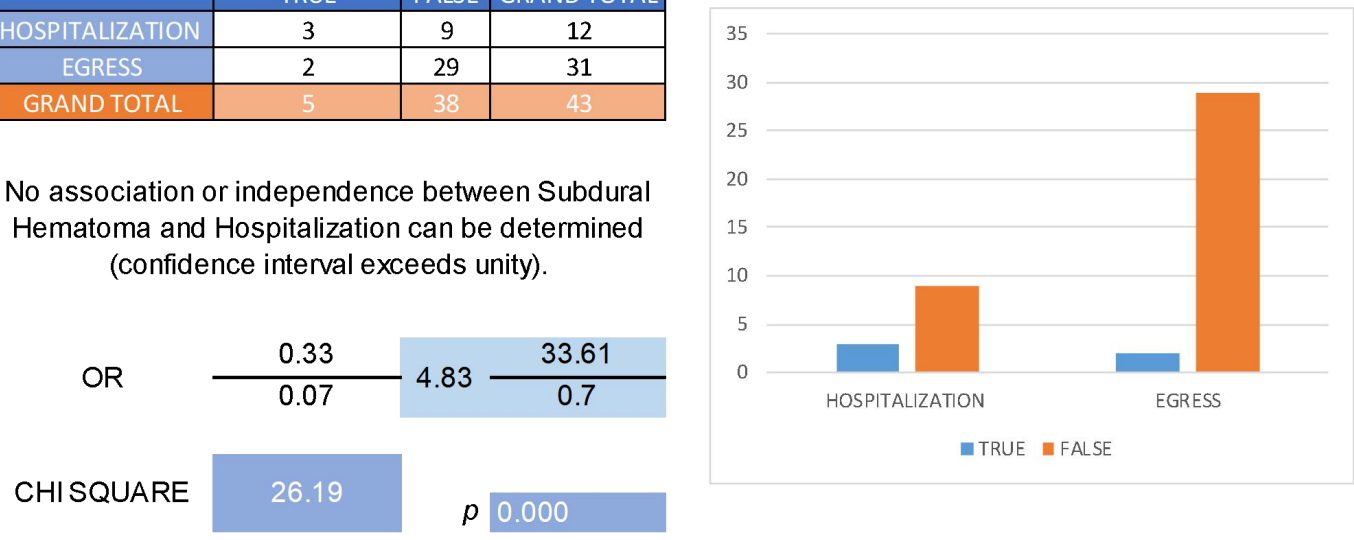

Figure 11. Relation the diameter of optic nerve and Hospitalization in patient with Subdural Hematoma 


\begin{tabular}{|c|c|c|c|}
\hline \multirow{2}{*}{$n$} & \multicolumn{3}{|c|}{ EDEMA } \\
\cline { 2 - 4 } & TRUE & FALSE & GRAND TOTAL \\
\hline HOSPITALIZATION & 0 & 12 & 12 \\
\hline EGRESS & 26 & 5 & 31 \\
\hline GRAND TOTAL & 26 & 17 & 43 \\
\hline
\end{tabular}

Cerebral Edema is associated with Hospitalization, but the OR can not be determined because it is an irrational number.

OR

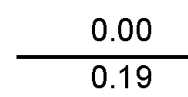
0.00

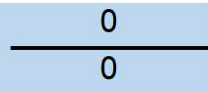

CHISQUARE

\subsection{4}

$$
p 0.000
$$

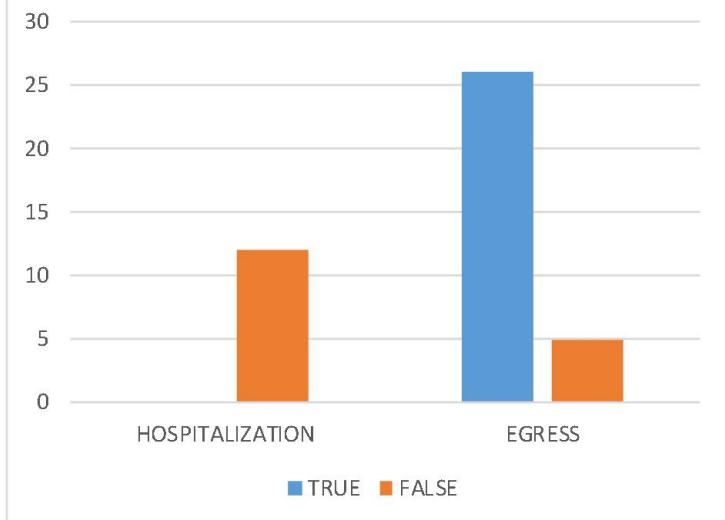

Figure 12. Relation the diameter of optic nerve and Hospitalization in patient with Edema

Table 1. Classification of patients depending on the Trauma Mechanism

\begin{tabular}{cc}
\hline TRAUMA MECHANISM & TOTAL \\
\hline Motorcycle accident & 4 \\
Run over & 9 \\
Fall or Height & 2 \\
Car crash & 9 \\
\hline Auomovilistic shock or Ejection Vehicle & 2 \\
\hline Wound by projectile by firearm & 1 \\
Contour trauma & 13 \\
Crushing injury & 1 \\
\hline
\end{tabular}

Table 2. Patients with DVNO Elevation and outcome.

\begin{tabular}{|c|c|}
\hline DVNO & DESTINATION \\
\hline $5.2 \mathrm{MM}$ & HOSPITALIZATION \\
\hline $5.1 \mathrm{MM}$ & HOSPITALIZATION \\
\hline $6.4 \mathrm{MM}$ & DEATH \\
\hline $5.5 \mathrm{MM}$ & DEATH \\
\hline
\end{tabular}




\begin{tabular}{|c|c|}
\hline $5.5 \mathrm{MM}$ & DEATH \\
\hline $5.8 \mathrm{MM}$ & DEATH \\
\hline $6.5 \mathrm{MM}$ & DEATH \\
\hline $6.0 \mathrm{MM}$ & DEATH \\
\hline $5.07 \mathrm{MM}$ & CRANIECTOMY \\
\hline $6.1 \mathrm{MM}$ & CRANIECTOMY \\
\hline $5.8 \mathrm{MM}$ & HIGH \\
\hline
\end{tabular}

Table 3. Trauma Mechanism in patients with high DVNO.

\begin{tabular}{|c|c|}
\hline DVNO & TRAUMA MECHANISM \\
\hline $\mathbf{5 . 0 7} \mathbf{M M}$ & AUTOMOTIVE SHOCK WITH VEHICLE EYECTION \\
\hline $\mathbf{6 . 1} \mathbf{M M}$ & ACCIDENT ON MOTORCYCLE \\
\hline $\mathbf{6 . 4} \mathbf{M M}$ & TRAUMA CONTUSO \\
\hline $\mathbf{5 . 5} \mathbf{M M}$ & ACCIDENT ON MOTORCYCLE \\
\hline $\mathbf{5 . 5} \mathbf{M M}$ & ATROPING \\
\hline $\mathbf{5 . 8} \mathbf{M M}$ & ATROPING \\
\hline $\mathbf{5 . 8} \mathbf{M M}$ & CAR CRASH \\
\hline $\mathbf{5 . 2} \mathbf{M M}$ & TRAUMA CONTUSO \\
\hline $\mathbf{5 . 1} \mathbf{M M}$ & CAR CRASH \\
\hline $\mathbf{6 . 5} \mathbf{M M}$ & WOUND BY PROJECTILE \\
\hline $\mathbf{6 . 0} \mathbf{M M}$ & CAR CRASH \\
\hline
\end{tabular}

Table 4. Primary and secondary lesions associated with patients with high DVNO.

\begin{tabular}{|c|c|}
\hline SKULL FRACTURE & $\mathbf{3}$ \\
\hline CRANIUM FRACTURE SINKING & 2 \\
\hline HEMORRHAGE CONTUSION & 7 \\
\hline SUBDURAL HEMATOMA & 4 \\
\hline SUBARACHNOID HEMORRHAGE & 5 \\
\hline EPIDURAL HEMATOMA & 3 \\
\hline NEUMOENCEFALO & 1 \\
\hline
\end{tabular}


Table 5. Suggestive Findings of Cerebral Edema in CT in Patients with High DVNO.

\begin{tabular}{|c|c|}
\hline ERECTION OF FURROWS AND CISSURES & $\mathbf{1 0}$ \\
\hline LOSS OF RELATIONSHIP GRAY AND WHITE SUBSTANCE & 3 \\
\hline VENTRICULAR COMPRESSION & 7 \\
\hline CEREBRAL HERNIATION & 1 \\
\hline
\end{tabular}

Table 6. Glasgow Scale in Patients with High DVNO.

\begin{tabular}{|l|l|}
\hline DVNO & GLASGOW \\
\hline $\mathbf{5 . 0 7} \mathbf{M M}$ & 9 PTOS \\
\hline $\mathbf{6 . 1} \mathbf{M M}$ & 4 PTOS \\
\hline $\mathbf{6 . 4} \mathbf{M M}$ & 3 PTOS \\
\hline $\mathbf{5 . 5} \mathbf{M M}$ & 4 PTOS \\
\hline $\mathbf{5 . 5} \mathbf{M M}$ & 3 PTOS \\
\hline $\mathbf{5 . 8 5} \mathbf{M M}$ & 6 PTOS \\
\hline $\mathbf{5 . 8} \mathbf{M M}$ & 13 PTOS \\
\hline $\mathbf{5 . 2} \mathbf{M M}$ & 5 PTOS \\
\hline $\mathbf{5 . 1} \mathbf{M M}$ & 3 PTOS \\
\hline $\mathbf{6 . 5} \mathbf{M M}$ & 6 PTOS \\
\hline $\mathbf{6 . 0} \mathbf{M M}$ & 3 PTOS \\
\hline
\end{tabular}

Table 7. Pupils in patients with high DVNO.

\begin{tabular}{|c|c|}
\hline DVNO & PUPILS \\
\hline $\mathbf{5 . 0 7} \mathrm{MM}$ & ISOCORICAS \\
\hline $\mathbf{6 . 1} \mathrm{MM}$ & ANISOCORIA \\
\hline $\mathbf{6 . 4} \mathrm{MM}$ & MIDRIASIS \\
\hline $\mathbf{5 . 5} \mathrm{MM}$ & ANISOCORIA \\
\hline $\mathbf{5 . 5} \mathrm{MM}$ & ISOCORICAS \\
\hline $\mathbf{5 . 8 5} \mathrm{MM}$ & ANISOCORIA \\
\hline $\mathbf{5 . 8} \mathrm{MM}$ & ISOCORICAS \\
\hline $\mathbf{5 . 2} \mathrm{MM}$ & MIOTICS \\
\hline
\end{tabular}




\begin{tabular}{|l|l|}
\hline $5.1 \mathrm{MM}$ & ANISOCORIA \\
\hline $6.5 \mathrm{MM}$ & ANISOCORIA \\
\hline $6.0 \mathrm{MM}$ & ANISOCORIA \\
\hline
\end{tabular}

\section{DISCUSSION}

The increase in intracranial pressure due to any intracranial pathology can cause cerebral ischemia secondary to a decrease in cerebral perfusion pressure. The determination of the increase in ICP is very important in terms of preventing possible brain damage and death.

The measurement of intracranial pressure is performed by invasive methods as mentioned above, however these methods have important complications, which is why we recently have at hand non-invasive methods of measuring intracranial pressure as in this case the ultrasound was demonstrated of the Diameter of the sheath of the optic nerve.

The DVNO normal in healthy adults is from $3.7 \mathrm{~mm}$ to $5 \mathrm{~mm}$, in this study it was demonstrated that in those patients with a DVNO greater than $5 \mathrm{~mm}$ they presented changes in the computed tomography, such as data of cerebral edema, intracranial hemorrhage and skull fracture This was also related to higher mortality, higher rate of hospitalization and worse prognosis.

The anisocoria is defined as an unequal diameter of the pupils of the eyes, a difference of 1 $\mathrm{mm}$ between the pupil diameter is physiological, this difference can be pathological when the difference is greater than $1 \mathrm{~mm}$, in this study it was also shown that of the 10 patients, 6 presentedanisocoria, which also shows a relationship with the increase in DVNO, as well as an increase in PIC.

Nowadays the DVNO measurement using the ocular USG has no specific contraindication. It is a non-invasive technique, which can be performed using equipment that we can have available in any emergency department.

In this article we used DVNO ultrasound as an indicator of the increase in ICP, which helped us with an early treatment of HIC and guided us to the possible complications and management of these patients, a study that in patients with TBI severe hemodynamically unstable patients could be performed at the patient's bedside without the need for mobilization to another unit. 
Our results show that the USG DVNO is a good indicator of the increase in ICP, as well as allowing us to detect other pathologies of the orbit. The ocular ultrasound provides us with a fast, effective and low cost method in the indirect measurement of the ICP, as well as the possible changes or lesions expected in the computed tomography, this we confirm with the patients in which they had an DVNO less than $5 \mathrm{~mm}$ in which no significant changes were found in the tomography and the prognosis and intrahospital stay was better.

\section{CONCLUSIONS}

Our study demonstrated that the USG DVNO can be as effective as a tomography, Glasgow scale and clinic in the diagnosis of intracranial hypertension, as well as possible secondary injuries, likewise it allowed us a timely management and prediction of mortality and intrahospital stay our patients.

Ultrasound is a non-invasive and innocuous imaging study for the patient, as well as being a low-cost study, which leads to a greater benefit inearly diagnosis and consequent medical treatment in patients who come to the emergency department for conditions such as traumatic brain injury, preeclampsia, ocular trauma and lumbar puncture in which intracranial hypertension syndrome is suspected.

\section{REFERENCES}

[1] ErdalKomut, MD, NalanKozaci, PhD, MD, BedriyeMügeSönmez, MD, FevziYilmaz, MD, SevalKomut, MD, ZelihaNilgünYildirim, MD, İnanBeydilli, MD, CihatYel, MD. Bedside sonographic measurement of optic nerve sheath diameter as a predictor of intracranial pressure in ED. American Journal of Emergency Medicine. 34 (2016); 963-967.

[2] HizirKazdal, AyhanKanat, HuseyinFindik, Ahmet Sen, Bulent Ozdemir, Osman ErsegunBatcik, OzcanYavasi, Mehmet FatihInecikli. Transorbital Ultrasonographic Measurement of Optic Nerve Sheath Diameter for Intracranial Midline Shift in Patients with Head Trauma. World Neurosurg. (2016) 85: 292-297.

[3] Dr. Martín de Jesús Sánchez-Zúñiga. Tratamiento de la hipertensión endocraneana.Paciente en estado crítico. Vol. 30. Supl. 1, Abril-Junio 2007. pp. S346S351. 
[4] Shigemori M, Abe T, Aruga T, Ogawa T, Okudera H, Ono J, et al. Guidelines for the management of severe head injury. 2nd edition. Guidelines from the Guidelines Committee on the Management of Severe Head Injury, the Japan Society of Neurotraumatology. Neurol Med Chir (Tokyo). 2012; 52:1-30.

[5] Part I. Guidelines for the management of severe traumatic brain injury. In: Management and prognosis of severe traumatic brain injury. (2) Update notice. Guidelines for the management of severe traumatic brain injury: cerebral perfusion pressure.

[6] Dr. Raúl Carrillo-Esper, Dr. José Martín Meza-Márquez. Trauma craneoencefálico.Vol. 38. Supl. 3 Octubre-Diciembre 2015. pp. S433-S434.

[7] Scott A. Marshall, MD, Atul Kalanuria, MD, Manjunath Markandaya, MBBS, Paul A. Nyquist, MD, MPH. Management of intracraneal Pressure in the Neurosciences Critical Care Unit. Neurosurg Clin N Am 24. (2013). 361-373.

[8] F. Gilo Arrojo, A. Herrera Muñoz y B. Anciones. Hipertensión intracraneal aguda. Neurología. 2010;25(Supl 1):3-10.

[9] Patrick Goeres, BS, Frederick A. Zeiler, MD, Bertram Unger, MD, PhD, DimitriosKarakitsos, MD, PhD, DS, Lawrence M. Gillman, MD, MMedEd, FRCSC, FACS. Ultrasound assessment of optic nerve sheath diameter in healthy volunteers. Journal of Critical Care 31 (2016) 168-171.

[10] GetawWorku Hassen, MD, PHD, Isaac Bruck, MD, PHD, Joseph Donahue, MD, Benjamin Mason, MD, Brett Sweeney, MD, Weafue Saab, MD, Jeremy Weedon, PHD, Neal Patel, MD,Kenneth Perry, MD, RDMS, Hussein Matari, MD, Rajnish Jaiswal, MD, and Hossein Kalantari, MD, MPH. Accuracy Of Optic Nerve Sheath Diameter Measurement By Emergency Physicians Using Bedside Ultrasound. The Journal of Emergency Medicine, Vol. 48, No. 4, pp. 450-457, 2015.

[11] Aaron Strumwasser, M.D., Rita O. Kwan, M.D., M.P.H., Louise Yeung, M.D., Emily Miraflor, M.D., Alex Ereso, M.D., Frederico Castro-Moure, M.D., Ph.D., Atul Patel, M.D., Javid Sadjadi, M.D., and Gregory P. Victorino, M.D. Sonographic Optic Nerve Sheath Diameter as an Estimate of Intracranial Pressure in Adult Trauma. Journal of Surgical Research 170, 265-271 (2011).

[12] Afshin AminiMD , Hamid Kariman MD , Ali ArhamiDolatabadi MD , Hamid Reza Hatamabadi MD, HojjatDerakhshanfar MD , Behnam Mansouri MD , Saeed Safari MD , RazieEqtesadi MD. Use of the sonographic diameter of optic nerve sheath to estimate intracranial pressure. American Journal of Emergency Medicine (2013) 31, 236-239. 
[13] Pedro J. Roque MD, Teresa S. Wu MD, Laura Barth MD, Dave DrachmanPhD , KaiNing Khor BA, MPH, Frank LoVecchio DO, MPH, Stephan Stapczynski MD. Optic nerve ultrasound for the detection of elevated intracranial pressure in the hypertensive patient. American Journal of Emergency Medicine (2012) 30, 1357-1363.

[14] Jose E. Irazuzta MD, FCCM, Martha E. Brown MSN, ARNP, Javed Akhtar MD. Bedside Optic Nerve Sheath Diameter Assessment in the Identification of Increased Intracranial Pressure in Suspected Idiopathic Intracranial Hypertension. Pediatric Neurology 54 (2016) 35-38.

[15] Susanne Bolesch, Frederic Von Wegner, Christian Senft, Matthias W. Lorenz. Transcranial Ultrasound to Detect Elevated Intracranial Pressure: Comparison of Septum Pellucidum Undulations and Optic Nerve Sheath Diameter. Ultrasound in Med. \& Biol., Vol. 41, No. 5, pp. 1233-1240, 2015.

[16] Lucas Ochoa-Pérez, Alejandro Cardozo Ocampo. Aplicaciones de la Ultrasonografía en el sistema Nervioso central para neuroanestesia y cuidado neurocritico. Revista Colombiana de anestesiología. Volumen 43, Issue 4, Octubre-Diciembre 2015. pp 314320. 